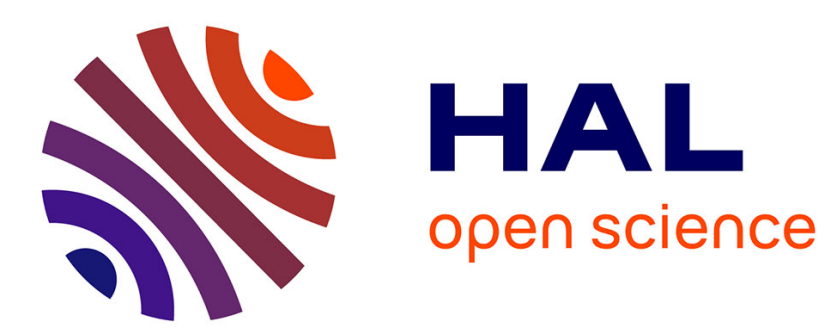

\title{
Potential of connected devices to optimize cattle reproduction
}

Marie Saint-Dizier, Sylvie Chastant-Maillard

\section{To cite this version:}

Marie Saint-Dizier, Sylvie Chastant-Maillard. Potential of connected devices to optimize cattle reproduction. Theriogenology, 2018, 112, pp.1-37. 10.1016/j.theriogenology.2017.09.033 . hal-01608602

\section{HAL Id: hal-01608602 \\ https://hal.science/hal-01608602}

Submitted on 27 May 2020

HAL is a multi-disciplinary open access archive for the deposit and dissemination of scientific research documents, whether they are published or not. The documents may come from teaching and research institutions in France or abroad, or from public or private research centers.
L'archive ouverte pluridisciplinaire HAL, est destinée au dépôt et à la diffusion de documents scientifiques de niveau recherche, publiés ou non, émanant des établissements d'enseignement et de recherche français ou étrangers, des laboratoires publics ou privés.

$$
\text { Copyright }
$$




\section{Accepted Manuscript}

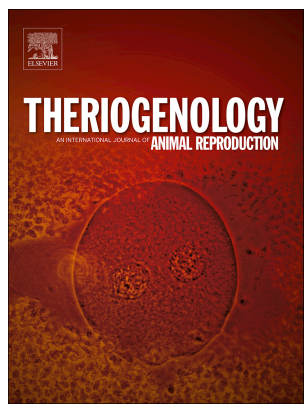

Potential of connected devices to optimize cattle reproduction

Marie Saint-Dizier, Sylvie Chastant-Maillard

PII: S0093-691X(17)30464-8

DOI: $\quad$ 10.1016/j.theriogenology.2017.09.033

Reference: THE 14280

To appear in: Theriogenology

Received Date: 19 April 2017

Revised Date: 19 September 2017

Accepted Date: 25 September 2017

Please cite this article as: Saint-Dizier M, Chastant-Maillard S, Potential of connected devices to optimize cattle reproduction, Theriogenology (2017), doi: 10.1016/j.theriogenology.2017.09.033.

This is a PDF file of an unedited manuscript that has been accepted for publication. As a service to our customers we are providing this early version of the manuscript. The manuscript will undergo copyediting, typesetting, and review of the resulting proof before it is published in its final form. Please note that during the production process errors may be discovered which could affect the content, and all legal disclaimers that apply to the journal pertain. 


\section{Potential of connected devices to optimize cattle reproduction}

3 Marie Saint-Dizier ${ }^{1}$, Sylvie Chastant-Maillard ${ }^{2}$

$4 \quad{ }^{1}$ Université François Rabelais de Tours, INRA, UMR 85 Physiologie de la Reproduction et

5 des Comportements, Centre INRA Val-de-Loire, Nouzilly, France. Corresponding author:

6 marie.saint-dizier@univ-tours.fr

$7 \quad{ }^{2}$ IHAP, Université de Toulouse, INRA, ENVT, Toulouse, France

8 Estrus and calving are two major events of reproduction that benefit from connected devices

9 because of their crucial importance in herd economics and the amount of time required for

10 their detection. The objectives of this review are to: 1) provide an update on performances

11 reached by sensor systems to detect estrus and calving time; 2) discuss current economic

12 issues related to connected devices for the management of cattle reproduction; 3) propose

13 perspectives for these devices. The main physiological parameters monitored separately or in

14 combination by connected devices are the cow activity, body temperature and rumination or

15 eating behavior. The combination of several indicators in one sensor may maximize the

16 performances of estrus and calving detection. An effort remains to be made for the prediction

17 of calvings that will require human assistance (dystocia). The main reasons to invest in

18 connected devices are to optimize herd reproductive performances and reduce labor on farm.

19 The economic benefit was evaluated for estrus detection and depends on the initial herd

20 performances, herd size, labor cost and price of the equipment. Major issues associated with

21 the use of automated sensor systems are the weight of financial investment, the lack of

22 economic analysis and limited skills of the users to manage associated technologies. In the

23 near future, connected devices may allow a precise phenotyping of reproductive and health 
24 traits on animals and could help to improve animal welfare and public perception of animal

25 production.

$26 \underline{\text { Keywords }}$ (5 max): estrus - calving - -monitoring - prediction - sensor

27 Cattle reproduction ensures meat and milk production together with herd replacement.

28 Reproductive events have to be precisely monitored to improve both the management and the

29 economic performance of cattle herds. Estrus and calving are the most sensitive steps: they

30 require time for their detection and once detected, crucial decisions, including insemination

31 and human intervention for newborn delivery, have to be made. There is evidence that the

32 sensitivity of estrus detection by visual observation ( 3 periods of 20 minutes each, every day)

33 of behavioral signs is limited (50-60\%) [1-3]. Furthermore, the visual detection method is

34 made more challenging by the short duration and low intensity of estrus signs in modern dairy

35 cows, the increasing herd sizes and the limited availability of labor time per cow [4-6]. These

36 two last factors have also probably contributed to the increase in the prevalence of dystocia

37 and stillbirths in dairy cattle. In Holstein dairy cows in the USA, the proportion of calvings

38 with a calf born dead at term or dying $24 \mathrm{~h}$ after birth is high, around $8 \%$, and the rate of

39 calvings considered dystocic reaches almost $14 \%$ [7-9].

40 In that context, sensors, i.e. devices measuring a physiological or behavioral parameter of

41 individual cows and enabling automated, on-farm detection of its changes (also called

42 "connected devices"; figure 1) [10], are potent tools for estrus and calving management in the

43 field (figure 2). The objectives of this review were to: 1) provide an update on performances

44 reached by sensor systems to detect estrus and calving time; 2) discuss current economic

45 issues related to connected devices for the management of cattle reproduction; 3) propose

46 perspectives for these devices. Sensors measuring a physiological parameter on animals but

47 with yet no automated data transmission, such as thermal cameras, estrus patches or blood 
assays, were considered off topic. In addition, even if field data may be available for some of them, only connected devices supported by published scientific data are being reviewed.

\section{Performances of connected devices}

Connected devices, are, like diagnostic tests, characterized by their sensitivity, specificity, positive predictive value (PPV) and negative predictive value (NPV). Nevertheless, the criteria on which the diagnostic value is to be evaluated may vary according to the practical objective of the device. For calving time prediction, sensors with high sensitivity (i.e. expressed by a high proportion of cows) are preferable with the trade-off of more false alarm (low specificity), in order to avoid human absence during calving needing assistance. The devices are also expected to be of high NPV (i.e. a high proportion of cows who do not express the monitored sign and do not calve during the 12 coming hours for example), for the farmer to limit surveillance especially at night. For estrus detection, a confirmation of estrus (by visual observation of physical signs) is often performed before AI: in that case, the sensitivity of sensors is more important than its specificity since in case of false positive, the AI will not be performed.

\section{I.1 Estrus detection}

\section{I.1.1. Physiological modifications at estrus}

Estrus in cows is associated with several behavioral and physiological changes, yet

with high variability between females due to environmental, herd and cow factors [6]. On the endocrine level, estrus is preceded by luteolysis, i.e. a rapid drop in milk and blood progesterone concentration. An average interval of $80 \mathrm{~h}$ was found between the drop in milk progesterone level below $5 \mathrm{ng} / \mathrm{ml}$ and ovulation in lactating dairy cows, however this interval was highly variable between individuals, ranging from 54 to $98 \mathrm{~h}$ [11]. The unique estrusspecific behavior is the standing-to-be-mounted behavior. However, this behavior is 
72 expressed by only approximately $60 \%$ of housed modern dairy cows [4, 5]. Mounting

73 behaviors, although not estrus-specific, were reported to be more frequent than mounting

74 acceptance behaviors during estrus and were recorded to occur in $90 \%$ of estrus periods in

75 cattle [5]. The global activity of the cow, defined as the number of steps or the total number of

76 animal movements, is also increased during estrus. Recorded thanks to pedometers in

77 Holstein cows housed in a free stall, number of steps started to increase on average $29 \mathrm{~h}$,

78 ranging from 22 to $39 \mathrm{~h}$, before the time of ovulation [12]. However, up to $10 \%$ of lactating

79 dairy cows do not exhibit any increase in activity before ovulation [13]. In parallel to this

80 increase in activity, the body temperature transiently increases of around $0.3^{\circ} \mathrm{C}-0.4^{\circ} \mathrm{C}$ at the

81 time of estrus compared to the luteal phase, in both cold and hot seasons $[14,15]$.

82 Connected devices designed for estrus detetction are based on the monitoring of these

83 behavioural and/or physiological parameters considered separately or combined.

\section{I.1.2. Monitoring of the standing-to-be-mounted behavior}

85 The standing-to-be-mounted behavior may be detected by a rump-fixed pressure sensor with radiotelemetric transmission of mounting data (available under the name HeatWatch® DDX

87 Inc., Denver, CO). Overall, the reviewed performances of HeatWatch ranged from 37 to $94 \%$ for sensitivity (defined as the rate of correctly detected estrus periods among all estrus periods) and from 77 to $100 \%$ for predictive positive value (PPV, defined as the rate of correctly detected estrus periods among all emitted alerts) [16, 17].

91 Comparison between Heatwatch and visual observation for estrus detection gave discordant results, probably due to differences in breeds and management systems. In beef heifers kept outdoors, no difference was evidenced between Heatwatch and a twice daily observation [18].

94 Compared with thrice daily visual observations in dairy cows, the efficiency of estrus detection using Heatwatch was reported to be lower [19] or higher [1] on pasture, and 
96 equivalent [20] or higher [1] indoors. Moreover, Heatwatch sensitivity and PPV were found

97 lower in housed dairy cows than in pastured cows, with false positives due to the pressure of

98 the device against side bars of individual cubicles in housed cows [1]. Furthermore, it has

99 been reported that patches could come off or become displaced during mounting, resulting in

100 missed data [19].

101 Another system, developed in New Zealand, detects mounting acceptance thanks to a

102

103

104

105

traditional pressure-sensitive device (such as Kamar ${ }^{\circledR}$ ) but with an automatic camera-

recognition of its status (either missing, not-activated, or activated) at every milking session

[21]. The sensitivity of this camera-based system was comparable with that of visual

observation or Heatwatch but the PPV was slightly lower [21].

A new approach to identify estrus behaviors may be cow positioning in space using ultra-

wideband (UWB) radio technology [22]. Indoor, UWB technology can record positioning of a mobile unit with centimeter accuracy in the horizontal and less than $30 \mathrm{~cm}$ vertically. The analysis of 3-dimensional positions of 12 dairy cows with synchronized estrus and housed in a free-stall barn allowed the detection of both mounting and standing-to-be-mounted behaviors during estrus. Based on both behaviors, only one false positive out of 10 alerts was obtained [22]. These preliminary findings require confirmation in a larger number of animals and under various housing conditions.

\section{I.1.3. Monitoring of global activity}

Automatic activity monitoring systems (AAMS) for estrus detection consist in pedometers, neck-collar mounted activity-meters and 3D-accelerometers attached to the leg or the neck [16]. AAMS have been extensively tested in commercial indoor dairy farms [2, 3, 23, 24] as well as in pastured production systems [25-27] and their performance for automated estrus detection has been reviewed $[16,17,28]$. Using milk or blood progesterone serial assays as 
120 gold standard to identify the occurrence of estrus, the sensitivity of AAMS ranged from 59 to 94\%, their specificity from 90 to $100 \%$ and their PPV from 36 to $92 \%$ (Table 1) $[2,17,25-27$, 29, 30] . Compared with the visual observation ( 2 to 6 times a day, 10-30 min/observation) of estrus behaviors, AAMS were reported to be of equivalent [31] or higher [2, 3, 32] sensitivity, with less false positives [2, 3, 32]. In farms where cows are equipped with AAMS, the usefulness of maintaining visual observation to improve estrus detection rate is questionable. When both AAMS and visual detection were used in parallel, the sensitivity was higher than with AAMS alone but the PPV was decreased [3, 32] or not modified [2]. Few studies evaluated the relative performance of various AAMS devices in the same animals $[2,24,33$, 34]. From those studies, no clear conclusion can be reached regarding differences in performance between collar- and neck-mounted accelerometers.

A wide range of factors influencing the performance of connected pedometers and accelerometers for estrus detection, including methodological, technical or biological factors, have been identified and recently reviewed [17]. A constant methodological factor of variation among studies is the way a true estrus is defined. For instance, taking the visual observation of behavioral signs of estrus or the day of insemination to define a true estrus episode will underestimate the rate of silent ovulations and generate less false alarms than the use of serial milk or blood progesterone measurements, which give a reliable indication of ovulation [17, 28]. Regarding the technical aspects of the devices, the period, the time window for activity measurement and the threshold used in the algorithm to define an increase in activity as indicative of a true estrus consistently impact the performances of AAMS [12, 26, 29, 35]. Default thresholds values and algorithms are often set by manufacturers in marketed devices. Lowering the activity threshold, when possible, may increase the efficacy of detection but with the trade-off of more false positives, resulting in a lower specificity [25, 30]. 
144 In addition, numerous biological factors known to decrease behavioral expression of estrus

145 also affect the performance of AAMS. These include the rank of postpartum ovulation, the

146 poorest performance being recorded at the first postpartum ovulation [24, 27]; the milk yield

147 and peak milk production, a lower sensitivity being recorded with high-producing compared

148 with low-producing cows [2, 24, 27]; the body condition score (BCS), cows with higher BCS

149 at the time of estrus being more likely to be detected $[2,3,27]$; the parity, in that the

150 sensitivity was lower with cows in their third than in their first lactation [24]; the uterine

151 health, cows with no uterine infection being more likely to be detected [27]; and lameness, in

152 that AAMS displayed a lower sensitivity in male cows compared with non-lame cows [2, 30].

\section{I.1.4. Monitoring of body temperature}

154 Using a vaginal temperature sensor, the detection rates were $96 \%$ and $93-100 \%$ for natural and synchronized estrus, respectively, and were higher than or equal to those obtained with a pedometer [15]. Temperature sensors placed in the cows's reticulum as permanent bolus are currently marketed for early detection of health problems. Besides helping in health management, these devices could also be used to improve heat detection. The diagnostic values of such devices for estrus detection require specific study. Clearly, the specificity of such tool in different seasons, environmental temperatures and in case of transient fever has still to be evaluated for estrus detection.

\section{I.1.5. In-line monitoring of milk progesterone}

The Herd Navigator system (HN; DeLaval, Tumba, Sweden) automatically collects milk samples at milking robots or parlours to analyze progesterone, lactate dehydrogenase and beta-hydroxybutyrate to detect estrus, tissue damage and metabolic disorders, respectively.

167 When tested experimentally for estrus detection, HN detected 99\% of confirmed estrus (for 168 which an AI resulted in a pregnancy) and 93\% of ratified estrus (defined by a progesterone 
169 profile matching that of confirmed estrus) with a specificity of 94\% [36]. An average heat

7
detection rate of $95 \%$ was later confirmed in commercial herds in Denmark [37]. However, not much has been published on the field performance of $\mathrm{HN}$ system.

\section{I.1.6. Combined indicators to detect estrus}

In housed dairy cows, the efficacy of estrus detection was enhanced by combining an AAMS with an automated pressure-sensing device [31] or with a traditional heat patch [2] compared with each system alone. Nevertheless, in pastured Holstein cows and heifers, the combination of activity and rumination data analysis generated more false positive alerts than activity alone [30]. Beyond a reliable demonstration of its technical benefit, the multiplication of sensors in animals may not be economically sustainable.

Another more promising approach is the use of automated technologies monitoring several parameters at the same time. Applying machine-learning techniques to data collected by various AAMS in lactating cows, the best performance for estrus detection was obtained with either four continuously recorded behaviors (activity, resting time, rumination and feeding times) or the combined number of steps, lying bouts and lying time collected with accelerometers (Table 1) [14]. However, these data, obtained from a limited number of animals, require confirmation.

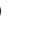

\section{I.2. Calving detection}

The detection of calving time has several objectives: (1) to predict the day before or the actual day of calving which allows to move the preparturient cow to an individual maternity pen; (2) to facilitate human surveillance and intervention under good conditions of hygiene and ensure better management of colostrum intake for calves and calf adoption for lactating cows. Thus, the first signal of a connected device for calving time prediction should ideally be delivered before the second stage of parturition, i.e. before the amniotic sac appears at the vulva, 
194 because moving a cow just before or during its expulsion can extend the time of delivery [38].

195 A further objective is to be warned of the onset of the calf expulsion and, ideally, of the necessity or not to assist the parturient cow. Indicators providing alerts over different time windows before calving, from a day to a few hours, are thus useful for calving management.

\section{I.2.1. Pre-calving physiological modifications}

Numerous behavioral changes have been associated with an impending calving, including restlessness, isolation from the rest of the herd, an increased number of lying/standing transitions and the repeated rising of the tail [39-42]. A decrease in the time spent lying together with an increase in the number of lying bouts were generally recorded over the last one to seven days before calving [43-48]. Thanks to pedometers and accelerometers, it was recently established that these changes generally increase in frequency and peaked in intensity during the last 6 to $12 \mathrm{~h}$ before the start of labor $[43,45,48]$.

Eating and rumination behaviors also change before calving. Evaluated with a noseband pressure sensor, the time spent eating started to decline as early as 10 days prepartum and were minimal on the day of calving [49]. Rumination duration decreases also close to the start of calving in both pasture-based [50]and confinement [46, 48, 49, 51-53] systems, with an abrupt decrease of 20-57\% over the last 6 to $10 \mathrm{~h}$ before delivery [46, 48, 54]. However, depending on the device used, housing conditions and herd management systems, a high variability in prepartum behaviors can be observed between studies $[46,50]$. In addition to behavioral changes, a gradual drop in body temperature of a few tenths of a

Celsius degree is exhibited by both primi- and multiparous cows about 2 days before parturition [55-57].

Connected devices currently marketed for calving detection include accelerometers detecting changes in global activity, inclinometers detecting tail raising, temperature sensors and 
218 devices inserted into the vaginal cavity or attached to the vulva to detect expulsion of fetal

219 membranes and calf [58]. Rumination sensors initially designed to detect health troubles were

220 also recently evaluated for their ability to predict calving time.

\section{I.2.1 Monitoring of activity}

223 Activity monitoring devices initially developed to detect estrus were recently used for an 224 automatic real-time and quantitative evaluation of pre-calving behavioural modifications in 225 dairy cattle [43-45, 47, 48, 50, 59, 60]. The continuous monitoring of lying bouts and lying 226 time, alone or combined, allowed to predict calving time within the next 6 to $24 \mathrm{~h}$ but with 227 high rates of false negatives and false positives: a sensitivity of $58 \%$ and a specificity of $61 \%$ 228 were recorded [48]. By developing an activity index combining the number of steps, lying 229 bouts and standing time, the calving time of Holstein dairy cows and heifers could be 230 predicted on average $6 \mathrm{~h}$ before its occurrence (from $2 \mathrm{~h}$ to $14 \mathrm{~h} 15$; more than $4 \mathrm{~h}$ in $76 \%$ of cows) [45]. Using the same device and applying three different machine-learning techniques

232 to the continuously recorded numbers of steps, lying bouts, lying and standing times during

233 the 21 prepartum days, the actual day of calving could be predicted with high accuracy in 234 Holstein dairy cows (78-89\% sensitivity, 94-98\% specificity and 42-73\% PPV and 99\% NPV) $235[46]$.

236 Automated image analysis is also a promising tool to detect prepartum behavioral changes

237 (standing, lying, eating and drinking): in a proof-of-concept study on eight cows placed in 238 individual maternity pens, $85-87 \%$ of calvings were predicted within 24 hours of their actual 239 occurrence [61].

\section{I.2.2. Monitoring of rumination and eating behaviors}


241 Numerous commercially available data-logging tools (collar-mounted microphone, noseband

242 pressure sensor or 3D-accelerometer) with telemetric data transmission were used to monitor

243 dairy cattle feeding and rumination behaviors before calving [46, 48-54, 62].

244 While the benefit of measuring eating behavior for the prediction of calving still needs to be

245 evaluated in cattle, the performance of automated rumination sensors was recently evaluated

246 for this purpose in dairy cows $[46,48,50]$. Using a collar consisting of an accelerometer and a

247 microphone, a threshold of $10 \%$ decline in rumination time gave the optimal combination of

$24870 \%$ sensitivity and $70 \%$ specificity to detect the day before calving in pasture-based dairy

249 cows [50]. Using the same collar and applying three machine-learning techniques, the day of

250 calving could be predicted with $44-78 \%$ sensitivity and $89-95 \%$ specificity in housed dairy

251 cows, but with a high number of false positives (PPV of 26-33\%) [46]. Thanks to a 3-

252 dimensional accelerometer attached to the ear tag and designed to monitor rumination, the

253 start of calving was best predicted within $6 \mathrm{~h}$ but with a poor performance $(63 \%$ sensitivity

254 and specificity, and only 11\% PPV) [48].

\section{$255 \quad$ I.2.3. Monitoring of body temperature}

256 For purposes of calving prediction, the characteristic prepartum drop in body temperature has

257 been successfully measured by a data-logging apparatus with telemetric transmission placed

258 either in the vagina $[48,56,63]$ or in the reticulo-rumen $[57,64]$ in both beef and dairy cows.

259 Changes in intra-ruminal temperature may be difficult to interpret because of the drop

260 following each water intake [65]. However, in two independent studies, analyses conducted

261 with all data or with the exclusion of temperature values below $37.7^{\circ} \mathrm{C}$, i.e. altered by water

262 intake, gave similar results [57, 64]: an average drop of at least $0.33^{\circ} \mathrm{C}$ was detected over the

263 last two days before parturition [57, 64]. 
264 A very limited number of studies evaluated the performance of the automatic measurement of

265 body temperature to predict a calving within the next $24 \mathrm{~h}$ or less $[48,56,57]$. Based on

266 vaginal temperature, the best indicators of calving within the next $24 \mathrm{~h}$ in dairy cows were a

267 cut-off drop of more than either $0.3^{\circ} \mathrm{C}$ (62-71\% sensitivity and $81-87 \%$ specificity) [56] or

$2680.1^{\circ} \mathrm{C}$ (74\% sensitivity and specificity) [48]. Using the reticuloruminal temperature, the best

269 test performance to predict calving time within $24 \mathrm{~h}$ in dairy cows was achieved with an

270 average drop of $\geq 0.2^{\circ} \mathrm{C}$ (69\% sensitivity and specificity) [57]. In both anatomical areas,

271 increasing the temperature threshold led to fewer false alarms (higher specificity) but lower

272 sensitivity (lower proportion of animals exhibiting the sign), thus a higher proportion of

273 animals that would be missed [56, 57]. For both organs, the prediction of calving within the

274 next $12 \mathrm{~h}$ gave slightly more false alarms than a prediction within the next $24 \mathrm{~h}$ (specificity of

$27569 \%$ and $64 \%$ for the vagina and reticulorumen, respectively)[48, 57]. A limitation of vaginal

276 temperature sensors is that they have to be inserted at least 10 days before the expected start

277 of calving for a correct determination of baseline values. Beside the risk of vaginal

278 inflammation, this delay may be difficult to respect regarding the variability in pregnancy

279 duration in cows [66].

\section{I.2.4. Combination of measurements}

282 Combining several indicators may maximize the performance of calving prediction in cows.

283 When the data from rumination time and global activity (collected by a collar-mounted

284 accelerometer) were combined with lying and standing activities (lying bouts, lying time,

285 number of steps and standing time collected by a leg-mounted accelerometer) and analyzed

286 using the machine-learning neural network analysis, test performances reach their maximal

287 values, with a sensitivity of $100 \%$, a specificity of $97 \%$, PPV of $60 \%$ and NPV of $100 \%$,

288 when compared with each set of data considered alone [46]. Accordingly, the combination of 
289 lying/standing activities with vaginal temperature and rumination time (all automatically

measured thanks to three different devices on the same dairy cows), gave the best results to predict parturition within the next 6 to $24 \mathrm{~h}$ compared to each indicator considered individually [48]. However, as stated above, multiplying sensors on animals is not costeffective. A single accelerometer attached at the eartag which monitors activity, rumination time, feeding time and ear temperature on an hourly basis was recently evaluated on 400 dairy cows for its ability to predict the start of calving [67]. As expected, the inclusion of these parameters, especially activity, rumination and temperature, improved the accuracy of prediction compared to a prediction based only on the expected date of calving [67]. With a fixed false positive rate of $1 \%$ (specificity of 99\%), the model developed allowed to predict $42 \%$ of calvings within a time-window of $3 \mathrm{~h}$ and $49 \%$ within $6 \mathrm{~h}$ [[67]. Overall, the best combination for a prediction of calving within a short time-window (less than $6 \mathrm{~h}$ ) included body temperature, rumination time $[48,67]$ and lying bouts [48]. This highlights the fact that the performance of a given indicator varies with its pattern of change and with the time interval chosen to define the alarm threshold. Furthermore, parameters like rumination time and lying bouts change abruptly in the last 6-12 h before expulsion whereas the global activity begins to change earlier $[48,67]$. This emphasizes the potential benefit of combining several parameters to provide long-term or short-term alarms.

\section{I.2.5 Automated detection of calf expulsion}

Vulvar devices detecting expulsion have to be sutured to the vulval lips of pregnant females close to the calving date. A first part is sutured on the left side of the vulva while a smaller mobile part is sutured on the right side $[68,69]$. The engagement of the calf in the birth canal separates the mobile part from the rest of the device and activates a radiowave signal, which triggers, via a receiver-transmitter apparatus, the sending of a text message to a mobile phone. Tested on Holstein cows and heifers in a confinement system, the sensitivity and the PPV 
314 were 100 and 95\%, respectively [68]. A GPS receiver was added to the device in order to

315 localize the parturient cow in extensive grazing areas [69]. Evaluated in a limited number of

316 animals (18 dairy and 8 beef cows), the sensitivity and PPV of the GPS-localizing system

317 were $100 \%$ and the geographical coordinates of the delivering female were correctly

318 transmitted for all cases expect one [69]. Nevertheless, since they only detect the second stage

319 of labor, these devices do not fill the first objective of calving prediction mentioned above,

320 that is to be warned before the onset of parturition to be able to move the cow into a calving

321 pen.

II. Economic issues of connected devices for cattle reproduction

\section{II.1. Motivations to invest}

325

326

327

Among 832 Canadian dairy farmers, 23\% used an AAMS and 10\% used it as their main tool

for reproduction management for both first and subsequent inseminations ( $96 \%$ of the users applied AMMS to cows, 27\% to heifers [70]). Connected devices may be more widely spread in Europe than in other continents due to high employee wages, relatively high prices for hormonal preparations, growing societal concerns regarding the use of hormones in animal production and consumer health, together with society and farmer concerns about animal welfare (linked to repeated drug administration). However, the current use of connected devices for reproduction management in cattle is still poorly documented. Michaelis et al. (2014) reported that approximately 1700000 automated activity monitoring tags have been sold worldwide and that approximately 100000 tags are currently used in dairy farms in Germany [3]. Approximately $20 \%$ of Dutch [71] and French (C. Allain, Idele, personal communication) dairy farms currently use automated estrus detection. 
337 The most frequently reported reason to adopt an AAMS in Canadian dairy herds was the desire to improve herd reproductive performance (81\% of respondents) [72]. In decreasing order of answers were then the lack of time to detect estrus (51\% of respondents), the chance to monitor health condition along with estrus (45\%), the desire to breed cows in natural estrus (44\%), the desire to reduce labor (39\%), the concern about frequent injections required in timed AI programs (35\%), the inability of workers to detect estrus $(23 \%)$ and going organic (3\%) [72]. In Dutch dairy farms, the main reasons for investing in connected devices for estrus detection were improving detection rates, gaining insights into the fertility of the herd, improving profitability of the farm and reducing labor [71].

\section{II.2 Impact on herd reproductive performances}

No published data is available concerning the impact of connected devices for calving detection on calf mortality rate or dam post-partum health including reproductive performances. However, the impact of devices allowing automated estrus detection on the global herd reproductive performance was recently evaluated. In the Dutch dairy farms investigated, investing in estrus detection sensors did not change the interval from calving to first service nor the age at first calving [73], probably because the rules on voluntary waiting period and age at first calving were unchanged after the investment. Conception rates for AI performed on estrus detected with mounting sensors were similar in dairy cows [19] but lower in beef heifers [18] than after visual estrus detection. Higher pregnancy rates were reached following inseminations performed in estrus detected with AAMS than after visual detection $[3,74]$.

When comparing the overall reproductive performance between the year before and the year after adoption of an AAMS for estrus detection in 505 Canadian dairy farms, a mean increase of $7 \%$ in the 21-day insemination risk (from 42 to $50 \%$ ) and of $2 \%$ in the 21 -day pregnancy risk (from 15 to 17\%) were recorded, whereas the conception risk per AI did not change [72]. 
362 The comparison between dairy herds using AAMS and timed-AI for more than $50 \%$ of inseminations did not show any difference in pregnancy rates, conception risk and insemination rates $[72,75]$. This means that for reproductive management in large dairy herds, AAMS could be an alternative to hormonal synchronization of estrus. However, the new technologies available for estrus detection do not solve the problem of $15-25 \%$ cows that

367 fail to ovulate after the voluntary waiting period $[76,77]$. For these anovulatory cows, the hormonal induction of estrus may remain the best option.

369 For further improvement of conception rate, some basic knowledge for optimal use of connected devices is also lacking. Manufacturers are expected to provide indications about the

371 delay between data acquisition and data processing to produce the alert, as well as the optimal time to perform AI once the alert is emitted. Short of the latter, the determination of the best

373 time to inseminate relative to the estrus alert is a challenge. The am-pm rule was established

374 in the 40's when estrus detection was only accomplished by visual observation. The earlier 375 detection of estrus potentially offered by automated estrus detection systems compared with 376 visual detection may lead to lengthen the interval between the estrus alert and insemination.

377 Nevertheless, ovulation was observed an average of 27-30 hours after estrus detection by 378 AAMS (with extremes of 21 and 39 hours) and pregnancy rates in dairy cows were reported 379 to be highest with inseminations performed 5 to $18 \mathrm{~h}$ after the AAMS alert, as recently 380 reviewed [17]. AI timing seems thus very similar to the 8-to-18-h interval found to be optimal 381 after visual detection of estrus in the field [78].

382 It is of note that automated sensors do not exclude expert human observation of the animals. A clinical examination of a cow detected in estrus by AAMS by the farmer, the inseminator and/or the vet remains necessary to compensate a low specificity of detection of such

385 automated devices. Moreover, the clinical exam remains the only way to detect genital 386 abnormalities preventing insemination, like endometritis. 
389

A major issue associated with the use of automated sensor systems for estrus detection is the heavy investment and the payback period [79]. It is noteworthy that the wish of the farmers to limit the investment may affect the performances of the devices. For example, limiting the number of vaginal thermometers may prevent the farmer to insert them long enough before calving.

The main reasons given by Dutch dairy farmers [71] and by North Americans [79, 80] for not investing in sensor systems (in general, not only for reproduction management) are economically related. The expected costs for 50 cows is $3-8 \mathrm{k} €$ for accelerometers, pedometers, vaginal thermometers, abdominal belts, 7-10 k€ for pedometers sensitive to the position (standing/lying) or mounting detectors. HerdNavigator system costs around $50 \mathrm{k} €$ as an initial investment, to which annual subscription of 55-80 $€ /$ cow. To the best of our knowledge, there is currently no data available on the economic outcome of implementing automated calving detection in cattle. Published data on the financial effects of implementing automated systems for estrus detection are scarce but they show globally economic benefits [81-84]. In a recent study, various scenarios of adoption of automated estrus detection were simulated in herds initially using $100 \%$ visual detection or $100 \%$ timed artificial insemination: the investment was found to be globally profitable and the payback period ranged from 1.6 years to more than 10 years, depending on the initial system and labor costs [84]. A userfriendly decision support tool was created by the authors for investment analysis, in which inputs comprise general and reproductive management practices and the cost of the proposed automated system, and outputs include the expected cost per day, the net present value, the pay-back period and the culling rate [84]. In another study, a comprehensive simulation model was used to study the technical and economic effects of implementing an AAMS, in a dairy 
412 farm of 130 cows $(8,310 \mathrm{~kg}$ milk/305 d./cow $)$ in the baseline scenario [83]. Assuming a 30-\%

413 increase (from 50 to $80 \%$ ) in the efficacy of estrus detection with AAMS compared with

414 visual detection and a slight decrease in the specificity of detection (from $100 \%$ to 95\%), the

415 use of AAMS led to a reduction of 16 days in the average calving interval, an increase in

416 average annual milk production of around $11,000 \mathrm{~kg}$ per farm, a parallel increase in the

417 annual number of inseminations (due to the increased numbers of estrus detected and

418 inseminations per calving) and calves, a reduction in the number of culled cows per year and a

419 reduction in labor input [83]. Overall, the investment was profitable, with a difference in

420 annual net cash flow between farms with and without AAMS of 2,827 € over a 10-year period

421 [83]. It is noteworthy that economic benefits depend on herd size. In the previous economic

422 simulation, the marginal financial effect was much lower, of $1,779 €$, for a herd of 65 cows,

423 and higher $(3,870 €)$ with a herd of 195 cows [83]. Also, the improvement in herd

424 sustainability when using connected devices clearly depends on the initial performances of the

425 herd (initial estrus detection, dystocia rate and neonatal mortality for calving detection), the

426 cost of the equipment and labor costs.

III. Perspectives for connected devices

429 The development of connected devices not only affects herd performances, as described

430 above, but also raises some technological and societal issues, together with perspectives for

431 the global cattle population (figure 3).

\section{III.1. Toward more polyvalent and easy-to-use systems}

433 Linked to the heaviness of investment, a major challenge of most connected devices for estrus

434 detection is the integration of supplementary data, e.g. on animal production, health, and

435 economic information, into a global management system to generate recommendations, i.e. to

436 inseminate or not a cow in estrus, to isolate a pregnant cow, to intervene or not during calving 
437 etc. [10]. With the exception of the HN system, none of the connected devices for estrus

438 detection integrates other information than the parameter monitored. In addition to

439 progesterone assays, the HN system integrates complementary data on the animal, e.g. post-

440 partum interval, milk production, negative energy balance (diagnosed thanks to beta-

441 hydroxybutyrate assays) that are helpful in determining, for each estrus period, a probability

442 of pregnancy if inseminated. The polyvalence of connected devices (i.e. their ability to

443 evaluate other aspects of cow management) is an asset for their practical and financial

444 acceptability in the field.

445 Concerning calving detection, the improper use of calving monitoring systems may lead to

446 premature interventions and expose parturient cow to a higher risk for post-partum genital

447 inflammation and infection. In order to help the farmer to decide to intervene or not, devices

448 should be developed to not only predict precisely the start of calving, but also to evaluate the

449 probability of dystocia in the coming calving. A technology that quantifies the duration of

450 calving from the onset of the first stage, i.e. the time at which uterine contractions begin, may

451 be a first approach to the identification of problematic calvings. To date, no device has been

452 specifically designed to predict abnormal calvings but the first results, based on the

453 continuous recording of prepartum activity, eating and/or drinking behavior, seem promising

454 [58]. Thereafter, algorithms associated with dystocia would have to be incorporated into

455 existing devices.

456 Polyvalence would also meet the need of easy-to-use devices. Lack of technical support and

457 of training for use of automated technologies are major obstacles to investment into connected

458 devices [79]. Among the most frequent reasons given for slow adoption by farmers of

459 automated monitoring systems were the lack of familiarity with technologies and the fear of

460 receiving too much information without any key for converting them into decisions [80], 
461 while the simplicity and ease-of-use were frequent arguments in the choice of a new

462 technology to be implemented on the farm [79].

\section{III.2 Phenotyping of reproductive and health traits}

464 Automated monitoring systems make it possible to reach a more precise characterization of

465 reproductive traits in cattle. The numerous connected devices give access to a large number of physiological parameters measured simultaneously in a large number of animals under various management conditions, in a non- (or minimally) invasive way and in a long-term perspective (ideally over the whole life of the animals). Such objective phenotypes are potent tools to explore biological issues underlying the expression of estrus, fertility, but also health. Important questions regarding the interval from the onset of increased activity and ovulation [12], the duration and intensity of estrus in relation to circulating estradiol concentrations [34] were revisited thanks to AAMS. Important questions regarding the interval from the onset of increased activity and ovulation [29], the duration and intensity of estrus in relation to circulating estradiol concentrations [28] were revisited thanks to AAMS. Similarly, AMMS provided the incidence of silent ovulations in Holstein dairy cows under various housing systems $[1,85]$. Endocrine fertility traits, defined from progesterone concentrations monitored in milk, have been suggested as alternative indicators for fertility in dairy cows because they are less biased by farm management decisions than classical traits derived from insemination and calving data $[86,87]$. The progesterone profiles generated post-partum on a large number of cows allowed to quantify the prevalence of atypical profiles, i.e. abnormalities in postpartum ovarian resumption, in various management situations [88]. In-line milk progesterone monitoring before and after insemination also evidenced a link between the progesterone profiles and the success rate of insemination in Holstein cows [89], underlying their interest for genetic selection on fertility traits in dairy cattle [86, 87]. 
485 On a population scale, the collection and analysis of these phenotypic data are precious for the

486 selection for estrus expression in dairy cattle. Similarly, the prevention of dystocia relies on a

487 systematic genetic evaluation for calving ease and marker assisted selection for calving traits

488 at the national and international levels [7]. Without automated monitoring, the determination

489 of phenotypes such as difficult calving is only possible through time-consuming observations

490 or subjective evaluation on limited numbers of animals. Connected devices allow the

491

492

493

494

495

phenotyping of peripartum events in a large number of animals in a variety of environments and management systems and as such, may be useful tools for accurate genetic evaluation of calving ease in cattle and to select females with high genetic index for this trait. A major challenge for sensor systems in reproduction is to integrate a high number of additional data on individual animals and their environment to produce not only more appropriate advice to the farmer, but also robust tools for selection and an integrated understanding of cattle in its farm and management conditions.

\section{III.3 Improving animal welfare and public perception of animal production}

Devices that have to be inserted into the vagina and left for several weeks, even months, and vulvar devices detecting expulsion which need a surgical suture to the vulva lips, are questionable in regard to animal welfare. Although the risks for health have not been evaluated so far, vaginal infection, irritation and wall thickening (limiting vaginal dilatation) could be expected with such devices.

However, globally, connected devices used for estrus and calving detection offer benefits for animal welfare. The prediction of calving time and accurate identification of cows in need of assistance provide a clear opportunity to improve calf and dam welfare during the peripartum period [90]. It is noteworthy that dystocia is considered by veterinarians as one of the most painful condition for cows [91, 92] and that more than $40 \%$ of calvings require assistance [93]. 
510 Providing a timely appropriate care at calving is crucial for the survival of the newborn calf,

511 for the dam's post-partum health and for the subsequent culling risk [9, 90]. Permanent

512 automated devices could also be helpful to improve the early diagnosis of health disorders

513 during the transition period [51]. Moreover, despite requiring receivers for data collection,

514 connected devices used in reproduction monitoring do not forbid pasture access. Hormonal

515 synchronization of estrus and timed artificial insemination (AI) protocols have been widely

516 adopted in the United States $[94,95]$ to overcome the time-consuming detection of estrus by

517 visual observation. In Europe, the average size of herds is globally lower and the use of

518 hormonal treatments is less. However, apart from the added cost of treatment, the growing 519 opposition of consumers and producers to the systematic use of hormones, makes hormonal 520 synchronization unacceptable in the management of cattle reproduction. This context gave a

521 specific interest to the automation of estrus detection.

522 By increasing reproduction efficacy, connected devices are expected to increase cow

523 longevity, which is positive from an animal welfare perspective as well as economically. With

524 the increasing concern of public opinion for animal welfare, connected devices have the

525 potential to make livestock farming more transparent and improve the public perception of 526 cattle production.

\section{Conclusion}

529 Connected devices for cattle reproduction were initially designed and scientifically evaluated

530 for estrus detection, mainly based on activity, behavioral or hormonal measurements. Their

531 indications now tend to be extended to calving detection, with a marked lack of published

532 validation. Wide perspectives are being opened by these devices in the field of reproduction:

533 beyond improvements in cattle reproductive performance, they may generate improvements in 
534 the breeders' quality of life and in animal welfare. They will also contribute to a better

understanding of cattle physiology, herd sustainability improvement and cattle selection.

Bovine reproduction is thus entering into the era of big data, offering the opportunity of deep

insights into physiology, diseases and cow's interactions with its environment. Inevitably, questions regarding the quality and the property of the data generated will have to be addressed in the near future to ensure their optimal valorization.

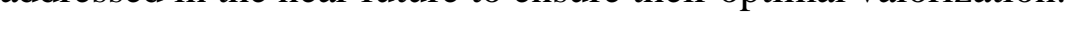

1

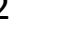

.

4
(1)

[1] Palmer MA, Olmos G, Boyle LA, Mee JF. Estrus detection and estrus characteristics in housed and pastured Holstein-Friesian cows. Theriogenology. 2010;74:255-64.

[2] Holman A, Thompson J, Routly JE, Cameron J, Jones DN, Grove-White D, et al. Comparison of oestrus detection methods in dairy cattle. Vet Rec. 2011;169:47.

[3] Michaelis I, Burfeind O, Heuwieser W. Evaluation of oestrous detection in dairy cattle comparing an automated activity monitoring system to visual observation. Reprod Domest Anim. 2014;49:621-8. [4] Kerbrat S, Disenhaus C. A proposition for an updated behavioural characterisation of the oestrus period in dairy cows. Applied Animal Behaviour Science. 2004;87:223-38.

[5] Roelofs J, Van Eerdenburg FJ, Soede NM, Kemp B. Various behavioral signs of estrus and their relationship with time of ovulation in dairy cattle. Theriogenology. 2005;63:1366-77.

[6] Roelofs J, Lopez-Gatius F, Hunter RH, van Eerdenburg FJ, Hanzen C. When is a cow in estrus? Clinical and practical aspects. Theriogenology. 2010;74:327-44.

[7] Mee J. Prevalence and risk factors for dystocia in dairy cattle - with emphasis on confinement systems. Western Canadian Dairy Seminar. Alberta, Canada: Department of Agricultural, Food and Nutritional Science, University of Alberta, Canada; 2012. p. 113-25.

[8] Lombard JE, Garry FB, Tomlinson SM, Garber LP. Impacts of dystocia on health and survival of dairy calves. Journal of Dairy Science. 2007;90:1751-60.

[9] Schuenemann GM, Bas S, Workman JD. Calving management: the first step in a successful reproductive program. In: J.S. Stevensen KSU, editor. Dairy Cattle Reproduction Conference. Indianapolis, Indiana2013. p. 8-17.

[10] Rutten CJ, Velthuis AG, Steeneveld W, Hogeveen H. Invited review: sensors to support health management on dairy farms. J Dairy Sci. 2013;96:1928-52. 
569 [11] Roelofs JB, Van Eerdenburg FJ, Hazeleger W, Soede NM, Kemp B. Relationship between

570 progesterone concentrations in milk and blood and time of ovulation in dairy cattle. Anim Reprod Sci.

571 2006;91:337-43.

572 [12] Roelofs JB, van Eerdenburg FJ, Soede NM, Kemp B. Pedometer readings for estrous detection and 573 as predictor for time of ovulation in dairy cattle. Theriogenology. 2005;64:1690-703.

574 [13] Valenza A, Giordano JO, Lopes G, Jr., Vincenti L, Amundson MC, Fricke PM. Assessment of an

575 accelerometer system for detection of estrus and treatment with gonadotropin-releasing hormone at

576 the time of insemination in lactating dairy cows. J Dairy Sci. 2012;95:7115-27.

577 [14] Dolecheck KA, Silvia WJ, Heersche G, Jr., Chang YM, Ray DL, Stone AE, et al. Behavioral and

578 physiological changes around estrus events identified using multiple automated monitoring

579 technologies. J Dairy Sci. 2015;98:8723-31.

580 [15] Sakatani M, Takahashi M, Takenouchi N. The efficiency of vaginal temperature measurement for

581 detection of estrus in Japanese Black cows. J Reprod Dev. 2016;62:201-7.

582 [16] Saint-Dizier M, Chastant-Maillard S. Towards an automated detection of oestrus in dairy cattle.

583 Reproduction in Domestic Animals. 2012;47:1056-61.

584 [17] Roelofs JB, van Erp-van der Kooij E. Estrus detection tools and their applicability in cattle: recent

585 and perspectival situation. Anim Reprod. 2015;12:498-504.

586 [18] Rae DO, Chenoweth PJ, Giangreco MA, Dixon PW, Bennett FL. Assessment of estrus detection by

587 visual observation and electronic detection methods and characterization of factors associated with

588 estrus and pregnancy in beef heifers. Theriogenology. 1999;51:1121-32.

589 [19] Xu ZZ, McKnight DJ, Vishwanath R, Pitt CJ, Burton LJ. Estrus detection using radiotelemetry or

590 visual observation and tail painting for dairy cows on pasture. J Dairy Sci. 1998;81:2890-6.

591 [20] Cavalieri J, Flinker LR, Anderson GA, Macmillan KL. Characteristics of oestrus measured using

592 visual observation and radiotelemetry. Anim Reprod Sci. 2003;76:1-12.

593 [21] Hempstalk K, Burke CR, Kamphuis C. Brief communication: Verification of an automated camera-

594 based system for oestrus detection in dairy cows. New Zeland Society of Animal Production.

595 Hamilton, New Zeland2013. p. 26-8.

596 [22] Homer EM, Gao Y, Meng X, Dodson A, Webb R, Garnsworthy PC. Technical note: a novel

597 approach to the detection of estrus in dairy cows using ultra-wideband technology. J Dairy Sci.

598 2013;96:6529-34.

599 [23] Jonsson R, Blanke M, Poulsen NK, Caponeti F, Hojsgaard S. Oestrus detection in dairy cows from

600 activity and lying data using on-line individual models. Computers and Electronics in Agriculture.

$601 \quad 2011 ; 76: 6-13$.

602 [24] Chanvallon A, Coyral-Castel S, Gatien J, Lamy JM, Ribaud D, Allain C, et al. Comparison of three

603 devices for the automated detection of estrus in dairy cows. Theriogenology. 2014;82:734-41.

604 [25] Kamphuis C, DelaRue B, Burke CR, Jago J. Field evaluation of 2 collar-mounted activity meters for

605 detecting cows in estrus on a large pasture-grazed dairy farm. J Dairy Sci. 2012;95:3045-56.

606 [26] Hockey C, Morton J, Norman S, McGowan M. Evaluation of a neck mounted 2-hourly activity

607 meter system for detecting cows about to ovulate in two paddock-based Australian dairy herds.

608 Reprod Domest Anim. 2010;45:e107-e17.

609 [27] Aungier SP, Roche JF, Sheehy M, Crowe MA. Effects of management and health on the use of

610 activity monitoring for estrus detection in dairy cows. J Dairy Sci. 2012;95:2452-66.

611 [28] Mottram T. Animal board invited review: precision livestock farming for dairy cows with a focus

612 on oestrus detection. Animal. 2016;10:1575-84.

613 [29] Lovendahl P, Chagunda MG. On the use of physical activity monitoring for estrus detection in

614 dairy cows. J Dairy Sci. 2010;93:249-59.

615 [30] Talukder S, Thomson PC, Kerrisk KL, Clark CE, Celi P. Evaluation of infrared thermography body

616 temperature and collar-mounted accelerometer and acoustic technology for predicting time of

617 ovulation of cows in a pasture-based system. Theriogenology. 2015;83:739-48.

618 [31] Cavalieri J, Eagles V, Ryan M, Macmillan KL. Comparison of four methods for detection of oestrus

619 in dairy cows with resynchronised oestrous cycles. Aust Vet J. 2003;81:422-5. 
620 [32] Nelson ST, Haadem CS, Nodtvedt A, Hessle A, Martin AD. Automated activity monitoring and 621 visual observation of estrus in a herd of loose housed Hereford cattle: Diagnostic accuracy and time 622 to ovulation. Theriogenology. 2017;87:205-11.

623 [33] Roelofs JB, Krijnen C, van Erp-van der Kooij E. The effect of housing condition on the 624 performance of two types of activity meters to detect estrus in dairy cows. Theriogenology.

625 2017;93:12-5.

626 [34] Silper BF, Madureira AM, Kaur M, Burnett TA, Cerri RL. Short communication: Comparison of 627 estrus characteristics in Holstein heifers by 2 activity monitoring systems. J Dairy Sci. 2015;98:3158-

62865.

629 [35] Sakaguchi M, Fujiki R, Yabuuchi K, Takahashi Y, Aoki M. Reliability of estrous detection in Holstein 630 heifers using a radiotelemetric pedometer located on the neck or legs under different rearing 631 conditions. J Reprod Dev. 2007;53:819-28.

632 [36] Friggens NC, Bjerring M, Ridder C, Hojsgaard S, Larsen T. Improved detection of reproductive 633 status in dairy cows using milk progesterone measurements. Reproduction in Domestic Animals. 634 2008;43 Suppl 2:113-21.

635 [37] Asmussen T. Herd Navigator or "How to benefit from frequent measurements". Proc ICAR 37th 636 Annual Meeting - Riga, Latvia, 31 mai-4 juin 2010. 2010:291-3.

637 [38] Proudfoot KL, Jensen MB, Heegaard RMH, von Keyserlingk MAG. Effect of moving dairy cows at 638 different stages of labor on behavior during parturition. Journal of Dairy Science. 2013;96:1638-46.

639 [39] Miedema HM, Cockram MS, Dwyer CM, Macrae Al. Behavioural predictors of the start of normal 640 and dystocic calving in dairy cows and heifers. Applied Animal Behaviour Science. 2011;132:14-9.

641 [40] Miedema HM, Cockram MS, Dwyer CM, Macrae Al. Changes in the behaviour of dairy cows 642 during the $24 \mathrm{~h}$ before normal calving compared with behaviour during late pregnancy. Applied 643 Animal Behaviour Science. 2011;131:8-14.

644 [41] Proudfoot KL, Huzzey JM, von Keyserlingk MAG. The effect of dystocia on the dry matter intake 645 and behavior of Holstein cows. Journal of Dairy Science. 2009;92:4937-44.

646 [42] Barrier AC, Haskell MJ, Macrae Al, Dwyer CM. Parturition progress and behaviours in dairy cows 647 with calving difficulty. Applied Animal Behaviour Science. 2012;139:209-17.

648 [43] Jensen MB. Behaviour around the time of calving in dairy cows. Applied Animal Behaviour 649 Science. 2012;139:195-202.

650 [44] Felton CA, Colazo MG, Bench CJ, Ambrose DJ. Large variations exist in prepartum activity among 651 dairy cows continuously housed in a tie-stall barn. Can J Anim Sci. 2013;93:435-44.

652 [45] Titler M, Maquivar MG, Bas S, Rajala-Schultz PJ, Gordon E, McCullough K, et al. Prediction of 653 parturition in Holstein dairy cattle using electronic data loggers. J Dairy Sci. 2015;98:5304-12.

654 [46] Borchers MR. "An evaluation of precision dairy farming technology adoption, perception, 655 effectiveness, and use": Theses and Dissertations--Animal and Food Sciences. Paper 45.

656 http://uknowledge.uky.edu/animalsci etds/45; 2015.

657 [47] Borchers MR, Chang YM, Proudfoot KL, Wadsworth BA, Stone AE, Bewley JM. Machine-learning658 based calving prediction from activity, lying, and ruminating behaviors in dairy cattle. J Dairy Sci.

659 2017;100:5664-74.

660 [48] Ouellet V, Vasseur E, Heuwieser W, Burfeind O, Maldague X, Charbonneau E. Evaluation of 661 calving indicators measured by automated monitoring devices to predict the onset of calving in 662 Holstein dairy cows. J Dairy Sci. 2016;99:1539-48.

663 [49] Braun U, Tschoner T, Hassig M. Evaluation of eating and rumination behaviour using a noseband 664 pressure sensor in cows during the peripartum period. BMC Vet Res. 2014;10:195.

665 [50] Clark CE, Lyons NA, Millapan L, Talukder S, Cronin GM, Kerrisk KL, et al. Rumination and activity 666 levels as predictors of calving for dairy cows. Animal. 2015;9:691-5.

667 [51] Soriani N, Trevisi E, Calamari L. Relationships between rumination time, metabolic conditions, 668 and health status in dairy cows during the transition period. J Anim Sci. 2012;90:4544-54.

669 [52] Schirmann K, Chapinal N, Weary DM, Vickers L, von Keyserlingk MAG. Short communication: 670 Rumination and feeding behavior before and after calving in dairy cows. Journal of Dairy Science. 671 2013;96:7088-92. 
672 [53] Calamari L, Soriani N, Panella G, Petrera F, Minuti A, Trevisi E. Rumination time around calving: an 673 early signal to detect cows at greater risk of disease. Journal of Dairy Science. 2014;97:3635-47.

674 [54] Büchel S, Sundrum A. Short communication: Decrease in rumination time as an indicator of the 675 onset of calving. Journal of Dairy Science. 2014;97:3120-7.

676 [55] Lammoglia MA, Bellows RA, Short RE, Bellows SE, Bighorn EG, Stevenson JS, et al. Body

677 temperature and endocrine interactions before and after calving in beef cows. Journal of Animal

678 Science. 1997;75:2526-34.

679 [56] Burfeind O, Suthar VS, Voigtsberger R, Bonk S, Heuwieser W. Validity of prepartum changes in

680 vaginal and rectal temperature to predict calving in dairy cows. Journal of Dairy Science.

681 2011;94:5053-61.

682 [57] Costa JB, Jr., Ahola JK, Weller ZD, Peel RK, Whittier JC, Barcellos JO. Reticulo-rumen temperature

683 as a predictor of calving time in primiparous and parous Holstein females. J Dairy Sci. 2016;99:4839-

68450.

685 [58] Saint-Dizier M, Chastant-Maillard S. Methods and on-farm devices to predict calving time in 686 cattle. Vet J. 2015;205:349-56.

687 [59] Maltz E, Antler A. A practical way to detect approaching calving of the dairy cow by a behavior

688 sensor. In: Cox S, editor. Precision Livestock Farming. The Netherlands: Wageningen Academic

689 Publishers; 2007. p. 141-6.

690 [60] Bachmann M, Wensch-Dorendorf M, Hoffmann G, Steinhofel I, Bothendorf S, Kemper N. The use

691 of pedometers as supervision tools for cows and mares in the prepartal period. Applied Animal

692 Behaviour Science. 2014;151:51-60.

693 [61] Cangar O, Leroy T, Guarino M, Vranken E, Fallon R, Lenehan J, et al. Automatic real-time

694 monitoring of locomotion and posture behaviour of pregnant cows prior to calving using online image

695 analysis. Computers and Electronics in Agriculture. 2008;64:53-60.

696 [62] Pahl C, Hartung E, Grothmann A, Mahlkow-Nerge K, Haeussermann A. Characteristics of

697 rumination behaviour around calving. In: Berckmans D, Vandermeulen J, editors. Precision Livestock

698 Farming 2013. Wageningen: Wageningen Academic Publishers; 2013. p. 784-92.

699 [63] Aoki M, Kimura K, Suzuki O. Predicting time of parturition from changing vaginal temperature

700 measured by data-logging apparatus in beef cows with twin fetuses. Animal Reproduction Science.

$701 \quad 2005 ; 86: 1-12$.

702 [64] Cooper-Prado MJ, Long NM, Wright EC, Goad CL, Wettemann RP. Relationship of ruminal

703 temperature with parturition and estrus of beef cows. Journal of Animal Science. 2011;89:1020-7.

704 [65] Bewley JM, Grott MW, Einstein ME, Schutz MM. Impact of intake water temperatures on

705 reticular temperatures of lactating dairy cows. J Dairy Sci. 2008;91:3880-7.

706 [66] Nogalski Z, Piwczynski D. Association of length of pregnancy with other reproductive traits in

707 dairy cattle. Asian-Australas J Anim Sci. 2012;25:22-7.

708 [67] Rutten CJ, Kamphuis C, Hogeveen H, Huijps K, Nielen M, Steeneveld W. Snesor data on cow

709 activity, rumination, and ear temperature improve prediction of the start of calving in dairy cows.

710 Computers and Electronics in Agriculture. 2017;132:108-18.

711 [68] Marchesi G, Leonardi S, Tangorra FM, Calcante A, Beretta E, Pofcher E, et al. Evaluation of an

712 electronic system for automatic calving detection on a dairy farm. Animal Production Science.

713 2013;53:1112-4.

714 [69] Calcante A, Tangorra FM, Marchesi G, Lazzari M. A GPS/GSM based birth alarm system for

715 grazing cows. Computers and Electronics in Agriculture. 2014;100:123-30.

716 [70] Denis-Robichaud J, Cerri RL, Jones-Bitton A, LeBlanc SJ. Survey of reproduction management on

717 Canadian dairy farms. J Dairy Sci. 2016;99:9339-51.

718 [71] Steeneveld W, Hogeveen H. Characterization of Dutch dairy farms using sensor systems for cow 719 management. J Dairy Sci. 2015;98:709-17.

720 [72] Neves RC, LeBlanc SJ. Reproductive management practices and performance of Canadian dairy

721 herds using automated activity-monitoring systems. J Dairy Sci. 2015;98:2801-11.

722 [73] Steeneveld W, Vernooij JC, Hogeveen H. Effect of sensor systems for cow management on milk

723 production, somatic cell count, and reproduction. J Dairy Sci. 2015;98:3896-905. 
724 [74] Yoshioka $\mathrm{H}$, Ito $\mathrm{M}$, Tanimoto $\mathrm{Y}$. Effectiveness of a real-time radiotelemetric pedometer for estrus 725 detection and insemination in Japanese Black cows. J Reprod Dev. 2010;56:351-5.

726 [75] Neves RC, Leslie KE, Walton JS, Leblanc SJ. Reproductive performance with an automated activity 727 monitoring system versus a synchronized breeding program. J Dairy Sci. 2012;95:5683-93.

728 [76] Royal MD, Darwash AO, Flint AP, Webb R. Declining fertility in dairy cattle: changes in traditional 729 and endocrine parameters of fertility. Animal Science. 2000;70:487-501.

730 [77] Petersson KJ, Gustafsson H, Strandberg E, Berglund B. Atypical progesterone profiles and fertility 731 in Swedish dairy cows. J Dairy Sci. 2006;89:2529-38.

732 [78] Martinez F, Kaabi M, Martinez-Pastor F, Alvarez M, Anel E, Boixo JC, et al. Effect of the interval

733 between estrus onset and artificial insemination on sex ratio and fertility in cattle: a field study.

734 Theriogenology. 2004;62:1264-70.

735 [79] Borchers MR, Bewley JM. An assessment of producer precision dairy farming technology use, 736 prepurchase considerations, and usefulness. J Dairy Sci. 2015;98:4198-205.

737 [80] Russell RA, Bewley JM. Characterization of Kentucky dairy producer decision-making behavior. J

738 Dairy Sci. 2013;96:4751-8.

739 [81] van Asseldonk MAPM, Jalvingh AW, Huirne RBM, Dijkhuizen AA. Potential economoc benefits

740 from changes in management via information technology applications on Dutch dairy farms: a

741 simulation study. Livestock Production Science. 1999;60:33-44.

742 [82] Ostergaard S, Friggens NC, Chagunda MG. Technical and economic effects of an inline

743 progesterone indicator in a dairy herd estimated by stochastic simulation. Theriogenology.

$744 \quad 2005 ; 64: 819-43$.

745 [83] Rutten CJ, Steeneveld W, Inchaisri C, Hogeveen H. An ex ante analysis on the use of activity

746 meters for automated estrus detection: to invest or not to invest? J Dairy Sci. 2014;97:6869-87.

747 [84] Dolecheck KA, Heersche G, Jr., Bewley JM. Retention payoff-based cost per day open regression

748 equations: Application in a user-friendly decision support tool for investment analysis of automated

749 estrus detection technologies. J Dairy Sci. 2016;99:10182-93.

750 [85] Ranasinghe RM, Nakao T, Yamada K, Koike K. Silent ovulation, based on walking activity and milk 751 progesterone concentrations, in Holstein cows housed in a free-stall barn. Theriogenology.

752 2010;73:942-9.

753 [86] Tenghe AM, Berglund B, Wall E, Veerkamp RF, de Koning DJ. Opportunities for genomic

754 prediction for fertility using endocrine and classical fertility traits in dairy cattle. J Anim Sci.

755 2016;94:3645-54.

756 [87] Sorg D, Wensch-Dorendorf M, Schopke K, Martin G, Schafberg R, Reinhold N, et al. Genetic

757 analysis of new progesterone-based fertility traits in dairy cows measured on-farm. J Dairy Sci. 2017.

758 [88] Saby-Chaban C, Zhang W, Fournier R, Servien R, Villa-Vialaneix N, Chastant-Maillard S.

759 Progesterone and betahydroxybutyrate in line measurements for a better description and

760 understanding of Holstein cows fertility in field conditions. ECPLF. Nantes, France2017.

761 [89] Bruinje TC, Gobikrushanth M, Colazo MG, Ambrose DJ. Dynamics of pre- and post-insemination 762 progesterone profiles and insemination outcomes determined by an in-line milk analysis system in 763 primiparous and multiparous Canadian Holstein cows. Theriogenology. 2017;102:147-53.

764 [90] Palombi C, Paolucci M, Stradaioli G, Corubolo M, Pascolo PB, Monaci M. Evaluation of remote

765 monitoring of parturition in dairy cattle as a new tool for calving management. BMC Veterinary

766 Research. 2013;9:191.

767 [91] Huxley JN, Whay HR. Current attitudes of cattle practitioners to pain and the use of analgesics in 768 cattle. Veterinary Record. 2006;159:662-8.

769 [92] Laven RA, Huxley JN, Whay HR, Stafford KJ. Results of a survey of attitudes of dairy veterinarians 770 in New Zealand regarding painful procedures and conditions in cattle. New Zealand Veterinary 771 Journal. 2009;57:215-20.

772 [93] Mee JF. Prevalence and risk factors for dystocia in dairy cattle: A review. Veterinary Journal.

773 2008;176:93-101. 
774 [94] Caraviello DZ, Weigel KA, Fricke PM, Wiltbank MC, Florent MJ, Cook NB, et al. Survey of 775 management practices on reproductive performance of dairy cattle on large US commercial farms. J 776 Dairy Sci. 2006;89:4723-35.

777 [95] Fricke PM, Carvalho PD, Giordano JO, Valenza A, Lopes G, Jr., Amundson MC. Expression and 778 detection of estrus in dairy cows: the role of new technologies. Animal. 2014;8 Suppl 1:134-43.

779

780 
782 LEGEND

783 Figure 1: Operating principle of connected devices. The connected device equipping the cow 784 emits a signal that is processed by a specific software and thereby interpreted by an algorithm 785 into a biological information. In case this information is deviant from thresholds set up by the 786 manufacturer, an alarm is transmitted to the farmer, on a computer and/or on a mobile phone.

787 This alarm implies an action. To be undertaken by the farmer for the cow (insemination, 788 calving assistance)

789 Figure 2: Available sensors for estrus and/or calving detection.

790 Figure 3: Issues and perspectives of connected devices in the field of reproduction. 
791 Table 1: Performances of automated activity monitoring systems (AAMS) for estrus detection in dairy cattle.

\begin{tabular}{|c|c|c|c|c|c|c|c|}
\hline $\begin{array}{l}\text { Parameter(s) } \\
\text { monitored }\end{array}$ & Type of device & $\begin{array}{l}\text { Housing } \\
\text { conditions }\end{array}$ & Sensitivity $^{a}$ & Specificity $^{b}$ & $\mathbf{P P V}^{\mathrm{c}}$ & $\begin{array}{l}\text { Number } \\
\text { of } \\
\text { animals }\end{array}$ & Ref. \\
\hline Activity & Collar-mounted accelerometer & Indoors & $59 \%$ & & $94 \%$ & 67 & \multirow[t]{2}{*}{ [2] } \\
\hline Number of steps & Leg pedometer & Indoors & $63 \%$ & & $74 \%$ & 67 & \\
\hline Activity & Collar-mounted accelerometer & Pasture & $60-70 \%^{d}$ & $99 \%$ & $68-80 \%^{d}$ & & [25] \\
\hline Activity & Neck collar activity-meter & Indoors & $79-91 \%^{d}$ & $90-98 \%^{d}$ & $40-73 \%^{d}$ & 64 & \multirow[t]{2}{*}{ [26] } \\
\hline Activity & Neck collar activity-meter & Pasture & $87-94 \%^{d}$ & $90-98 \%^{d}$ & $41-76 \%{ }^{d}$ & 135 & \\
\hline Activity & Collar-mounted accelerometer & Indoors & $56-84 \%$ & $96-100 \%{ }^{d}$ & & 647 & [29] \\
\hline Activity & Collar-mounted accelerometer & Pasture & $72 \%$ & 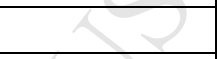 & $67 \%$ & 89 & [27] \\
\hline Activity & Collar-mounted accelerometer & Pasture & $78-80 \%^{d}$ & $57-94 \%$ & $67-70 \%{ }^{d}$ & 30 & \multirow[t]{2}{*}{ [30] } \\
\hline Rumination & Collar-mounted accelerometer & Pasture & $35 \%$ & $69 \%$ & $14 \%$ & 30 & \\
\hline $\begin{array}{l}\text { Activity, resting time, } \\
\text { rumination and } \\
\text { feeding times, ear } \\
\text { surface temperature }\end{array}$ & $\begin{array}{l}\text { Ear-attached accelerometer } \\
\text { with temperature sensor }\end{array}$ & Indoors & $100 \%^{\mathrm{e}}$ & $99-100 \%{ }^{\mathrm{e}}$ & $99-100 \%{ }^{\mathrm{e}}$ & 18 & [14] \\
\hline $\begin{array}{l}\text { Activity and } \\
\text { rumination time }\end{array}$ & Collar-mounted accelerometer & Indoors & $60-100 \%{ }^{\mathrm{e}}$ & $96-99 \%{ }^{\mathrm{e}}$ & $97-98 \%{ }^{\mathrm{e}}$ & 18 & \\
\hline $\begin{array}{l}\text { Number of steps, lying } \\
\text { bouts and lying time }\end{array}$ & Leg-mounted accelerometer & Indoors & $80-100 \%{ }^{\mathrm{e}}$ & $98-100 \%{ }^{\mathrm{e}}$ & $98-100 \%{ }^{\mathrm{e}}$ & 17 & \\
\hline Activity and lying time & Leg-mounted accelerometer & Indoors & $100 \%^{\mathrm{e}}$ & $90-97 \%^{e}$ & $91-97 \%^{\mathrm{e}}$ & 14 & \\
\hline
\end{tabular}

793 Milk or blood progesterone serial measurements were used as gold standard to confirm estrus events.

$794{ }^{a}$ Sensitivity (or efficiency) $=$ true positive alerts $(\mathrm{TP}) /(\mathrm{TP}+$ false negative alerts)

$795{ }^{\mathrm{b}}$ Specificity $=$ true negative alerts $(\mathrm{TN}) /(\mathrm{TN}+$ false positive alerts $(\mathrm{FP}))$

$796{ }^{c}$ Positive predictive value (or accuracy) $=\mathrm{TP} /(\mathrm{TP}+\mathrm{FP})$

$797{ }^{\mathrm{d}}$ Values vary depending on the threshold and/or the reference period used in the algorithm to define an increase in activity as an estrous period.

$798{ }^{e}$ Values were obtained using different machine-learning techniques (random forest, linear discriminant analysis and neural network). 
Table 1: Performances of automated activity monitoring systems (AAMS) for estrus detection in dairy cattle.

\begin{tabular}{|c|c|c|c|c|c|c|c|}
\hline $\begin{array}{l}\text { Parameter(s) } \\
\text { monitored }\end{array}$ & Type of device & $\begin{array}{l}\text { Housing } \\
\text { conditions }\end{array}$ & Sensitivity $^{\mathrm{a}}$ & Specificity $^{b}$ & $\mathbf{P P V}^{\mathbf{c}}$ & $\begin{array}{l}\text { Number } \\
\text { of } \\
\text { animals }\end{array}$ & Ref. \\
\hline Activity & Collar-mounted accelerometer & Indoors & $59 \%$ & & $94 \%$ & 67 & \multirow[t]{2}{*}{ [2] } \\
\hline Number of steps & Leg pedometer & Indoors & $63 \%$ & & $74 \%$ & 67 & \\
\hline Activity & Collar-mounted accelerometer & Pasture & $60-70 \%^{d}$ & $99 \%$ & $68-80 \%^{d}$ & & [25] \\
\hline Activity & Neck collar activity-meter & Indoors & $79-91 \%^{\mathrm{d}}$ & $90-98 \%$ d & $40-73 \%^{d}$ & 64 & \multirow[t]{2}{*}{ [26] } \\
\hline Activity & Neck collar activity-meter & Pasture & $87-94 \%{ }^{\mathrm{d}}$ & $90-98 \%^{d}$ & $41-76 \%{ }^{d}$ & 135 & \\
\hline Activity & Collar-mounted accelerometer & Indoors & $56-84 \%$ & $96-100 \%{ }^{d}$ & & 647 & [29] \\
\hline Activity & Collar-mounted accelerometer & Pasture & $72 \%$ & & $67 \%$ & 89 & [27] \\
\hline Activity & Collar-mounted accelerometer & Pasture & $78-80 \%^{d}$ & $57-94 \%$ & $67-70 \%^{d}$ & 30 & \multirow[t]{2}{*}{ [30] } \\
\hline Rumination & Collar-mounted accelerometer & Pasture & $35 \%$ & $69 \%$ & $14 \%$ & 30 & \\
\hline $\begin{array}{l}\text { Activity, resting time, } \\
\text { rumination and } \\
\text { feeding times, ear } \\
\text { surface temperature }\end{array}$ & $\begin{array}{l}\text { Ear-attached accelerometer } \\
\text { with temperature sensor }\end{array}$ & Indoors & $100 \%{ }^{\mathrm{e}}$ & $99-100 \%{ }^{\mathrm{e}}$ & $99-100 \%{ }^{\mathrm{e}}$ & 18 & \multirow[t]{4}{*}{ [14] } \\
\hline $\begin{array}{l}\text { Activity and } \\
\text { rumination time }\end{array}$ & Collar-mounted accelerometer & Indoors & $60-100 \%{ }^{\mathrm{e}}$ & $96-99 \%{ }^{\mathrm{e}}$ & $97-98 \%{ }^{\mathrm{e}}$ & 18 & \\
\hline $\begin{array}{l}\text { Number of steps, lying } \\
\text { bouts and lying time }\end{array}$ & Leg-mounted accelerometer & Indoors & $80-100 \%{ }^{\mathrm{e}}$ & $98-100 \%{ }^{e}$ & $98-100 \%{ }^{\mathrm{e}}$ & 17 & \\
\hline Activity and lying time & Leg-mounted accelerometer & Indoors & $100 \%^{\mathrm{e}}$ & $90-97 \%{ }^{\mathrm{e}}$ & $91-97 \%{ }^{\mathrm{e}}$ & 14 & \\
\hline
\end{tabular}

Milk or blood progesterone serial measurements were used as gold standard to confirm estrus events.

${ }^{\mathrm{a}}$ Sensitivity (or efficiency) $=$ true positive alerts $(\mathrm{TP}) /(\mathrm{TP}+$ false negative alerts $)$

${ }^{\mathrm{b}}$ Specificity $=$ true negative alerts $(\mathrm{TN}) /(\mathrm{TN}+$ false positive alerts $(\mathrm{FP}))$

${ }^{\mathrm{c}}$ Positive predictive value (or accuracy) $=\mathrm{TP} /(\mathrm{TP}+\mathrm{FP})$

${ }^{\mathrm{d}}$ Values vary depending on the threshold and/or the reference period used in the algorithm to define an increase in activity as an estrous period. 
${ }^{e}$ Values were obtained using different machine-learning techniques (rand 


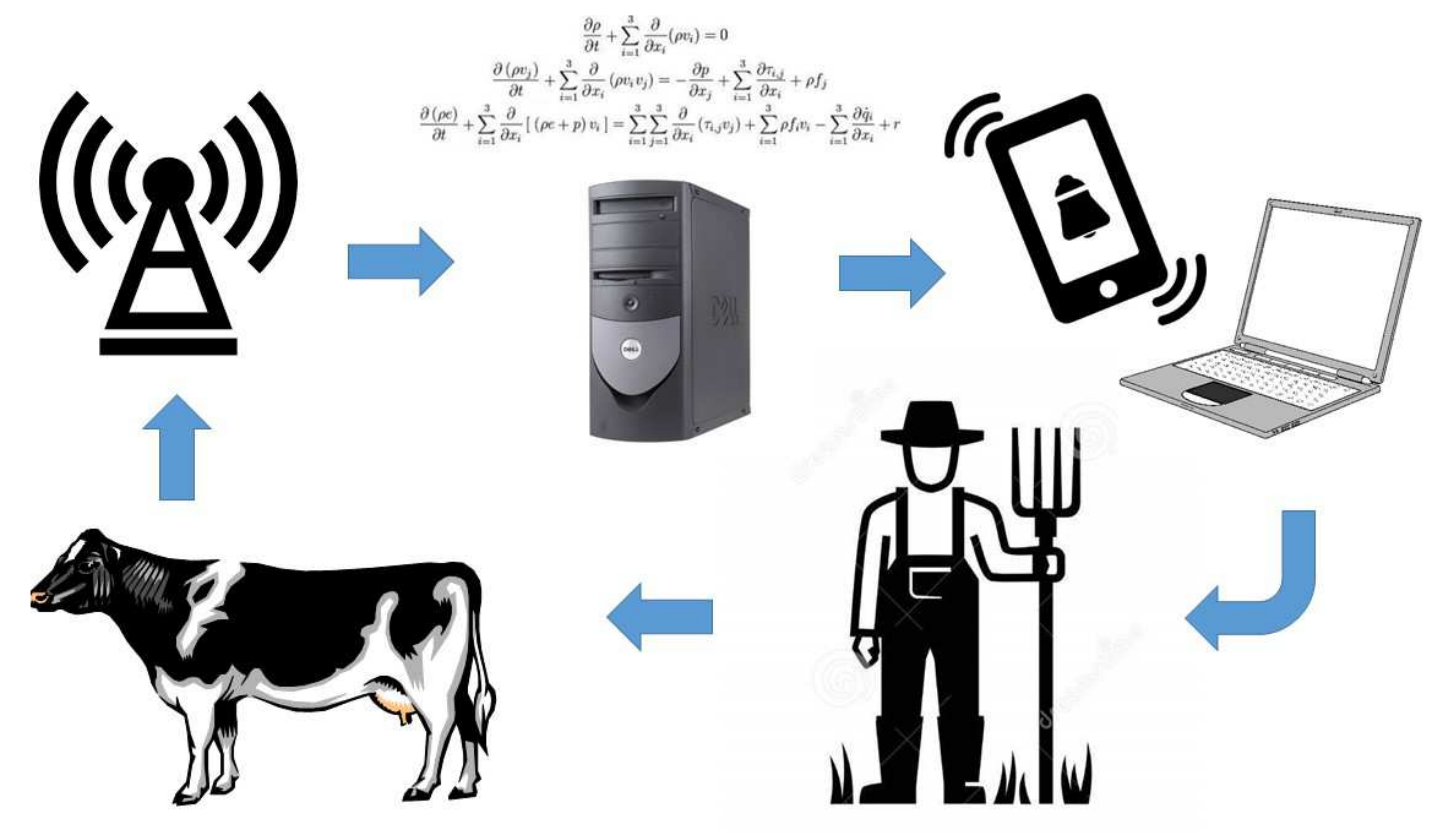




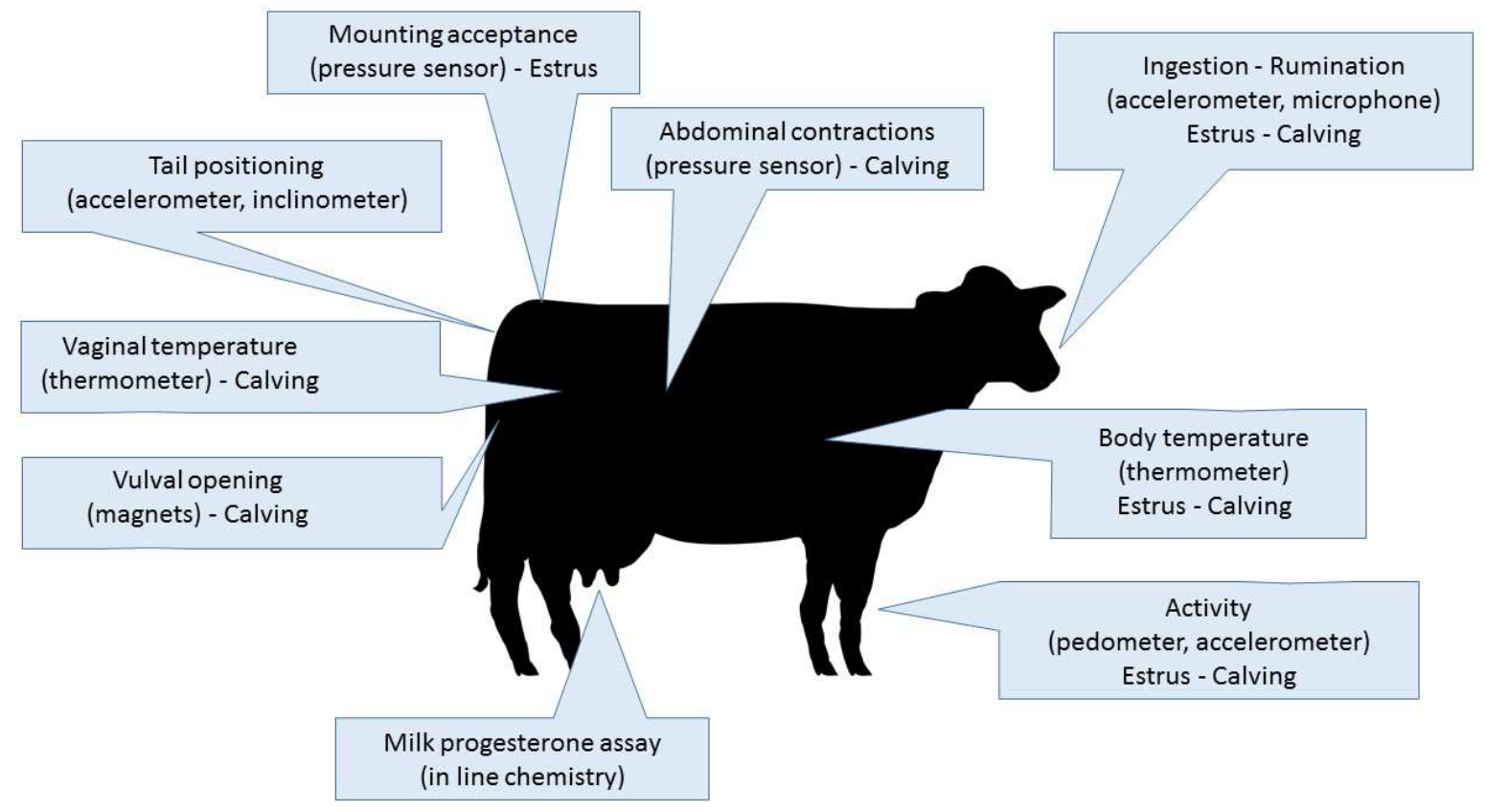



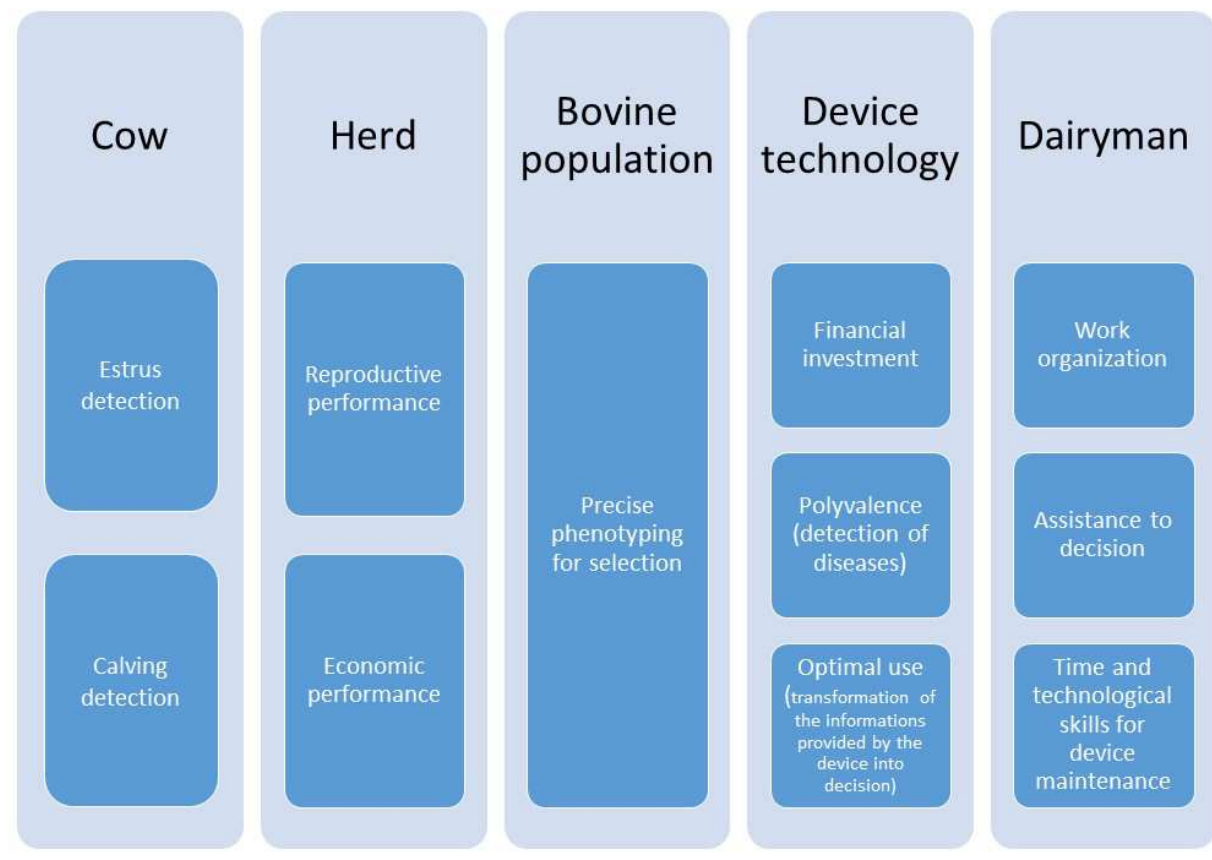

Societal

Animal welfare

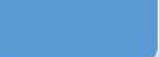

Limitation of

the use of

hormones

Man-animal

relationship 
Highlights

- Connected devices used in reproduction are designed for estrus detection and calving prevision.

- They aim at improving work organization, reproductive performances and animal welfare.

- Activity, ingestion/rumination and body temperature are the most frequently evaluated parameters.

- They represent a potent tool for large scale, non invasive phenotyping of cows in their environment. 